\title{
THE EDITOR'S ANNUAL REPORT
}

There are a few items to report for 1982. To begin with, there has been a gratifying increase in the number of submitted articles on economic subjects; other than that, the pattern of articles is fairly standard. Seventy-four articles were submitted to date; in the following list they are broken down according to discipline:

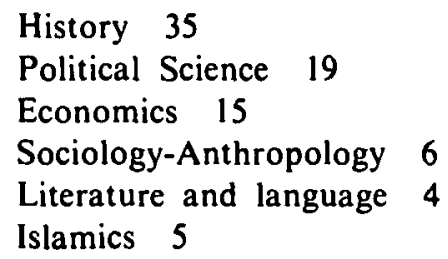

Of the seventy-four submitted, the editors have accepted twenty-two: one in Islamics, four in economics, five in political science, and eleven in history. The remainder were either returned to the authors for revision and resubmission, were rejected, or are still pending with the readers.

This year we have decided to treat review articles in the same fashion as regular articles. They will thus go through an editorial review rather than be treated as "simple" book reviews. Book reviews should not exceed 1,500 words. In the case of letters protesting the review of a book, we will allow the author of the reviewed book the right to a rebuttal and will publish it in the same issue as a rebuttal from the reviewer. The reason we have opted for this procedure rather than publishing the author's rebuttal in one issue, then the reviewer's rebuttal in another, is that it facilitates matters for the reader to see the two arguments side by side, rather than waiting for several months until the new issue appears, by which time the first argument is totally forgotten.

We have decided to divide the function of book review editor among three individuals, inasmuch as the task was becoming too much for one person to handle. Professor Michael Suleiman is now the social science editor, Professor Peter von Sivers is the history editor, and Professor Mona Mikhail is the literature and language editor. We have had some delays this year while our book review process was being organized, but I am sure that it has been streamlined by now, and that book reviews will appear promptly and with the minimum of delay.

There is one matter to which I should like to draw all our readers' attention, that is to the format of the articles submitted to the Journal. The rules for submission are clearly spelled out in the back cover of the Journal, along with 
the rules for transliteration. Transliterations are the responsibility of the authors; the editor and copy editor disclaim any responsibility for errors arising from incorrect transliteration. For the sake of economy, we need to cut down on the amount of revision that any article must go through, therefore it is imperative that articles conform to our requirements and standards, otherwise we shall be obliged to return them to the authors for re-writing, which is time-consuming and aggravating to all.

Lastly, I end on a sad note. Mrs. Teresa Joseph, who has been our production editor for over a decade, and who has done such excellent work for the Journal, decided to retire at the end of November 1982. We will miss her sorely. I know that I speak for all the readers and participants in the Journal in wishing her the very best, and above all in thanking her for her superlative service to IJMES. She will be very hard to replace. 